\title{
X Stories of a Technology Breakdown: How Digital Tools Influence Aesthetic and Artistic Options
}

\author{
Eunice Gonçalves Duarte \\ www.semaforo.cc \\ eunice.semaforo@gmail.com
}

\begin{abstract}
Departing from a practical approach to performance, the paper aims to analyse the performance "Xistórias - digital performance on the Schist Villages" - a participatory artistic work that aimed for the social development of small Schist Villages in Góis Municipality, in an underdeveloped region of Portugal, presented on November, 2013.
\end{abstract}

For several months two artists, a community organizer and a computer programmer worked together on the creation of this performance, along with 30 inhabitants from four different villages. During the process, besides the weather conditions and geographic isolation, several problems related to Internet connection and to mobile phone reception lead the team on the one hand to a research on the behaviour of technology devices, adjusting aesthetic and artistic options to the possibilities of the medium and on the other hand to a social action against digital exclusion in the territory.

The paper explores the frustration of team members and audience when experiencing adversities from constant technical failures. The author questions thus the possibility of technical failure having influence the artistic process and the artistic and aesthetic choices.

\section{Performance. Contemporary art. Low tech. Schist villages. Artistic failure. Ontology of performance. Live and mediatised.}

\section{INTRODUCTION}

"Qik is dead!"- said the text message on my mobile phone while I was performing. Qik was a free online tool that allowed to broadcast live using mobile phones. The message was from the computer programmer and co-worker in the performance and we were using Qik, along with other tools, in order to broadcast from a small village in Portugal to Lisbon. So...why am I receiving this message in the middle of my performance? If Qik is dead, I'm no longer broadcasting, thus making no sense to continue my actions.

The episode took place on November 2013 during the presentation of "Xistórias - digital performance on the Schist Villages" [xistorias.aldeiasdoxisto.pt], and even though it is a recent experience, its story is much older and so are the "failures" that marked the artistic process.

The project began its materialisation on May 2013, after several months of meetings, fundraising and gathering of local partners. The main idea was to create a digital performance in the small rural
Schist Villages in Góis Municipality, in an underdeveloped region of Portugal and my intention was to work with the inhabitants on a performance that would cross local rural storytelling with the research of a low tech technology for artistic development. The performance was designed to be broadcast in real time, through the Internet, to Lisbon.

On the day Qik died in the middle of my performance, I recalled Noël Carroll's essay "Philosophy and Drama: performance, interpretation, and intentionality" in which he opposes "drama as performance" to the "mass mediatized performance" saying that "we may complain when the lamp burns up in the middle of the screening and may even demand our money back. But we regard this as a technical failure, not an artistic failure." (2009)

Departing from a practical approach to performance creation, this paper aims to reflect on the position of art creation when dealing with technological failures: can I perform them, creating a work of art based on the possibility of failure? 


\section{A SCHIST STORY}

"Xistórias" followed a pattern used on my artistic research: the use of low tech devices, of everyday life, on the artistic creation of personal and intimate stories. In fact the first idea was to replicate a previous performance "A História é Clandestina" (Stealth Stories); a project based on Geoffrey Batchen's idea of snapshots as being part of the history of photography, claiming that they provide an emotional readings. It was not the idea of technology as "machine" that I was looking for; it was instead the ontological and anthropological arisen by a technology that is becoming more and more intimate and personal that triggered the project.

Telling the story of a family photo was one of the tool used to work with the community in "Xistórias" on the artistic practice: on the one hand helped to develop a pictorial thinking or to transpose ideas into images, on the other hand brought awareness on how technology is present in day-to-day life

"Xistórias" would follow "A História é Clandestina" adjusting urban concepts (the use of digital and mobile devices to transmit data and the intimacy of such media in everyday life) to the rural environment. Also the digital platform created for "A História é Clandestina" besides being used for artistic purposes would also work as a tool to connect several villages that were isolated, establishing a private network.

The initial proposal was very ambitious and demanded a great amount of human and technical resources. We had the know-how on digital platforms and on artistic creation but we were lacking territory knowledge. Therefore, at first, the project was considered "very urban", involving a great financial risk.

The project was funded by ADXTUR, the Agency for the Development of Tourism in the Schist Villages - an organisation created by 27 municipalities with the aim of a sustainable development of the region - and was supported by several local organisations such as Góis Town Council and Lousitânea - an NGO established in one of the villages (Aigra Nova) with near 10 years of work experience in the region and also responsible for collecting oral storytellings that served as basis for the artistic research with the community.

It was given a green light to start but we were asked to design a lighter version, i.e. to limit the territory to four villages (Aigra Nova, Aigra Velha, Pena and Comareira), to adjust the platform to the technology available on the spots and to reduce the number of team members. Also this would be considered as an experimental phase, being the ground zero for future collaborations.

\section{BEFORE THE PERFORMANCE, THE TECHNE}

The technological development of IT solutions for the project took into account its concepts: to develop a low tech tool, using free and opensource applications that could be easily manipulated by common users.

The platform chosen to broadcast was the VLC Media Player (http://www.videolan.org/vlc/). Although this application is best known as a simple media player, in fact it uses at its basis a FFmpeg project (http://www.ffmpeg.org/) library (encoding/decoding media), making VLC a very comprehensive free tool for streaming, both video and audio files.

Initially, as of "A História é Clandestina", this interface was developed for Windows computers due to the way hardware (camera, microphones, etc) is accessed. During the project "Xistórias" the interface and its backend was improved to add support for Linux and Mac OSX computers, mainly due to the increased market share of these platforms. This new support, alongside with other improvements, made the interface truly multiplatform. (see figure 1)

In order to ensure privacy and also to avoid complicated configurations of devices' network, it was used the VPN - Virtual Private Network LogMe In Hamachi (https://secure.logmein.com/products/hamachi/).

This software ensured that all users would be within the same private network and that each transmission would be encrypted and only available to project coordinators and/or to users.

\section{Other software following}

- DirectShow Java Wrapper (http://www.humatic.de/htools/dsj.htm)

- Qik (http://qik.com) for streaming video and audio files when using mobile devices

- ManyCam (http://manycam.com/) for multiplexing video cameras

The platform was programmed by Miguel Gomes, computer programmer,that also led the technical team in "A História é Clandestina". The medium was not totally new to us, we have been using it since 2010 and we were certain that the combination of such software would work although adjustment to the work with the community and to the artistic practice was needed. 


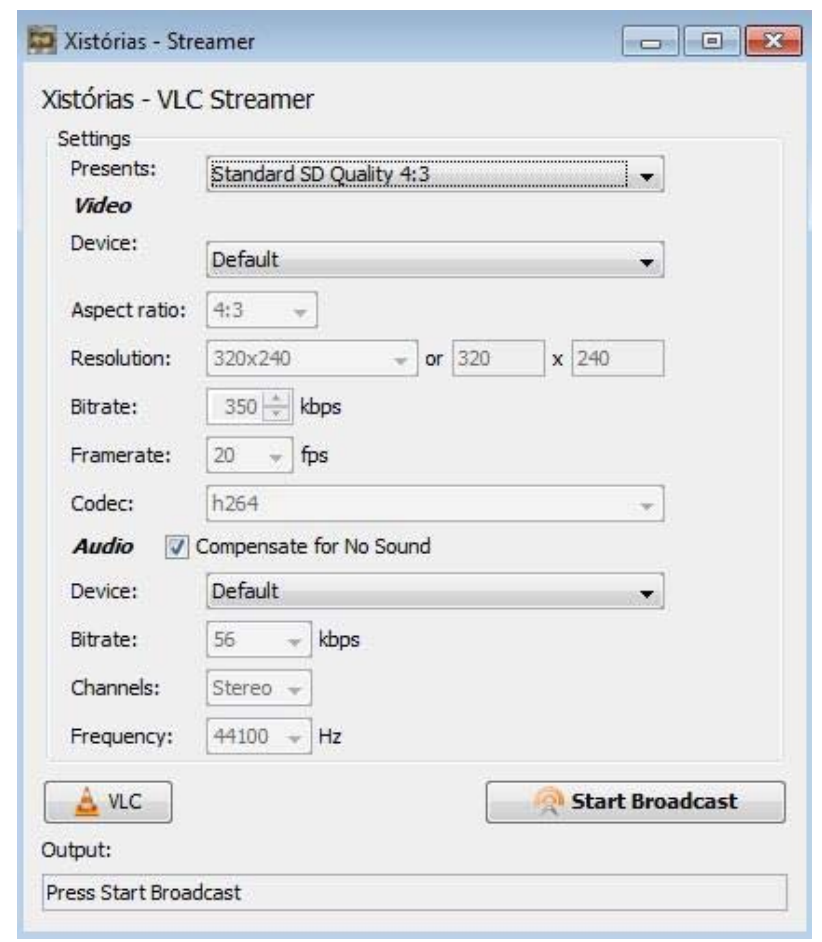

Figure 1: VLC programmed by Miguel Gomes

\section{NOT UNDER CONTROL}

Before the departure to the villages I have done all the homework I could from afar and listed several problems: means of transportation, accessibility, approach to the community, awareness of community's daily routine, community's digital literacy, different Internet services available in the area, and others that at first sight seemed harmless.

There was a great deal of risk involved - but all artistic process have this amount of risk, either working with a community or not, either using digital tools or not. In this specific research I was aiming at two different kinds of audience and two different presentations: a "live" presentation (audience would come to the villages to see the performance) and a "mediatized" presentation (audience in Lisbon experiencing the broadcast in real time) - for now I will refer to the performance presentations as "live" and "mediatized" to make my description more clear, although I consider both presentations as being live (see further development below).

"Live" performance was a site-specific composition that took place on the four schist villages and was performed by 30 people from the community. Part of it was broadcast to Lisbon where a master of ceremony and the technical team led the audience through the performance by reading stories used as background for the artistic work, showing prerecorded videos from the process (including short interviews with inhabitants from the villages) and, of course, the streaming.

This task is per se already too complex for a small team composed by two artists (performance art and visual art), a community organizer and a computer programmer. So, to shorten the team was a mistake in the first place and I must add that it was failure number one. The following problems struck us by surprise as they escaped our control:

- Internet connection and mobile phone reception

- Weather conditions and geographic isolation

- Number of spectators in the "Live" Performance

\subsection{Internet connection and mobile phone reception}

Lousitânea, our local partner, had an ADSL contract with a Portuguese Internet Service Provider that guaranteed enough range for the purpose of the project within this experimental phase. Also, they provided a space near their office for rehearsal and presentation. We could easily plug a cable to the router and assure a good quality broadcast. Wireless would to be used for streaming from mobile phones and when action would happen on the outside space.

The contract was a flop and our ordeal with Internet Service Providers began. Our tests showed that the speed of Internet service was below 1Mbit/s (see figure 2).

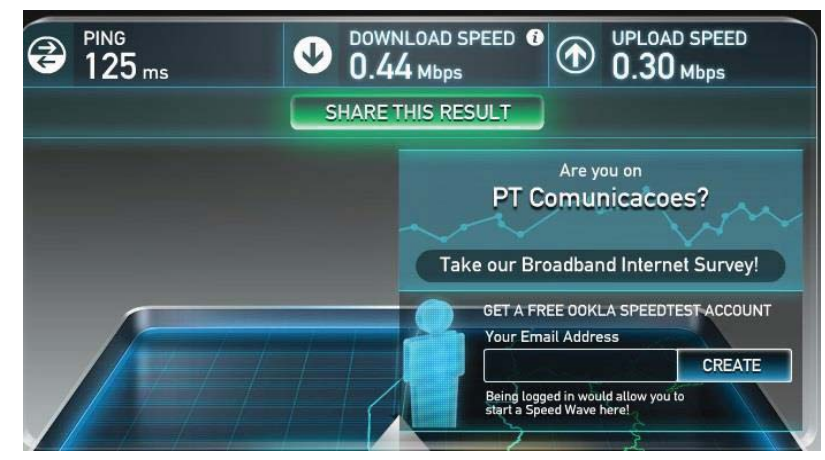

Figure 2: Testing Internet service using speedtest.net

When the company was asked about it they confirmed that in fact they could only provide $1 \mathrm{Mbit} / \mathrm{s}$ or less. They proposed a new contract to solve our problem, a more expensive one. The same happened with two other companies and both failed. We decided for a new contract but with another company. Failed. We turned to another company and again failed. All for the same reason: selling expensive contracts was their goal. We ended up using pre-paid mobile Internet sticks that by surprise worked better. 


\subsection{Weather conditions and geographic isolation}

The essence of the project, its urgency, was to bring awareness to the problem of abandonment by younger generations, thus proposing alternatives for social development. The hardness of working the land, poverty, poor access to schools, hospitals and other services plus the Portuguese colonial war in Africa were enough reasons for a generation to leave their homelands.

These four schist villages are situated between the Mountains of Lousã and Açor, at $770 \mathrm{~m}$ high. The weather is unstable, a microclimate when compared with the surrounding areas. Winter and summer accentuate their extremes: excessive cold or heat. Fog and wind are not strangers to the villages, bringing very dense clouds and/or humidity. This kind of weather also influences the reception of Internet signal. We learned that on cloudy and/or windy days it was much harder to get Internet or mobile phone connection. The same happened with T.V. signal, reinforcing isolation. It's a cycle difficult to break: decreasing the number of population in the area brings less amount of investment from private companies and from the state.

\subsection{Number of spectators in the "live" performance}

This was mistake number two: not establishing rules for spectators. I do not mean control the audience; instead I am referring to the aesthetic distance for spectators to construct their own readings. Spectator/performer protocol was broken: spectators were invited into people's houses to take part in the performance, shared food with inhabitants that were also performers, danced with them and we even described the audience as participants. It should not be a surprise to see them making use of their personal mobile phones and other mobile devices, during the performance, thus clogging wireless network.

Erika Fischer-Lichte's The Transformative Power of Performance: The New Aesthetics argues that the place of spectators is active, not passive, being the encounter of spectators and performers that determines its ontology, "being as an autopoietic feedback loop (...). It emerges out of the bodily copresence of different groups of participants and their confrontation and interaction. (...) In this sense performances are generated and determined by the actions and behaviour of all participants, no matter whether they are performers or spectators." (Fischer-Lichte 2009) and this happens even though spectators are not interfering directly into the action being performed. Spectators' emotional reaction (breathing, watching, sensing, etc..) can be perceived by all participants and it is enough to influence the course of the performance



Figure 3: Stills from the perforamance Xistórias: audience arriving to Aigra Velha (Schist Village) and broadcast to Lisbon from Aigra Nova (Schist Village)

Contemporary performance art focus on this role of spectators, provoking, teasing, abusing, calling them into action. From Antonin Artaud to Happenings and/or interactive digital works the treatment of audience is an important feature to consider when discussing the ontology of performance as well when analysing experimental work. And that happens on the basis that performance depends of this specific physical encounter.

In "Xistorias" the encounter with spectators happened at several levels: local (spectators traveling to the villages to take part in the performance) and both local and online, through the Internet (spectators traveled to the place of broadcast, in Lisbon). Both audiences were committed to the action in the performance, involved in the experience and emotionally attached. Therefore, both audiences were responsible for the course of performance.

\section{LIVE AND MEDIATISED}

The use of "new technologies" poses some problems to the ontology of performance: multiple mutations of technology throughout the twentieth century have contributed to blur the boundaries, forcing theoretical approaches to come up with different terms and concepts that aim at clear definitions. The major criticism appears from the idea of "live" as opposed to "mediatized".

Erika Fischer-Lichte, when arguing on the definition of performance, outlines specific arguments that were studied and observed on the research project "Kulturen des Performativen" (Performing culture): 


\begin{abstract}
"1. performance comes into being by the bodily co-presence of actors and spectators, by their encounter and interaction; 2. What happens in performances is transitory and ephemeral. Nonetheless, whatever appears in its course comes into being hic et nunc and is experienced as present in a particularly intense way; 3. A performance does not transmit pregiven meanings. Rather, it is the performance which brings forth the meanings that come into being during its course. 4. Performances are characterized by their eventness. The specific mode of experience they allow for is a particular form of liminal experience."
\end{abstract}

(Fischer-Lichte 2004)

This argument leads to the conclusion that performance is an experience of interaction between performers and spectators, here and now (hic et nunc), without predetermined meanings, it happens in its course, and as a consequence performance is an event that cannot be repeated. Fischer-Lichte leaves no space for the idea of mediatization as part of performance practice.

Opposing these arguments, Philip Auslander places the discussion in a broader cultural and political perspective. In "Against Ontology: Making Distinctions between Live and the Mediatized", Auslander points out that even "live" performance are in our times contaminated by the audiovisual language: "we no longer have a choice. The televisual is an intrinsic and determining element of our cultural formation (...) seeing it as the cultural context" (Auslander 1997).

Perhaps a provocative proposal to performance practitioners, but let's consider that if "live" is in itself contaminated by media it is not possible for performance art to escape the cultural surroundings, thus in contemporary performance there is not a reason to continue to draw the line, creating an opposition; cutting edge artistic work lives on liminal experiences.

As said before, I considered "Xistórias" a "live" performance, though I do not want to place the discussion on the subject of genre, because digital performance is in itself a hybrid concept. I would argue that beyond the relationship created with the spectator one must also consider aesthetic options and the conceptual discourse when establishing performative elements on local and "online".

"Xistórias" aesthetics relates to experimentations with media towards the creation of a performance; media is present even when appears only as a conceptual idea and not as a device. Technology is the liaison that connects all elements in performance. Therefore when the worst scenario to the creation of a digital performance was drawn, our escape was to accept that we were going to fail. Ultimately, I and the team ended up developing research on the behaviour of technology devices, adjusting aesthetic and artistic options to the possibilities of the medium and understanding how vulnerable it was.

\section{IF YOU CANNOT BEAT THEM, JOIN THEM}

In the introduction to this paper, I have described how Qik died on the middle of my performance (as this paper is being written, Qik was shut down by Skype, which is the same as having a permanent death) and how that reminded me of Noël Carroll's essay on philosophy and drama.

Carroll brings a contribution toward the discussion of the ontology of performance. In his essay, he questions the meaning of drama, deconstructing its classic notion as a "dual-tracked or two-tiered art form (...) the art of composing plays texts (..) and the art of performing them." (Carrol2009) acknowledging the need to adjust these concepts to contemporary performance art, where the script may just be a plan and may not even be written but resides in the memory of the performer.

Drama as performance goes beyond the distinction of "creator" (the one with the intention) and the "executors" (the interpreters). Performance "is not a consequence of a process of physical causation. It involves mentation.". Intention stresses on performance as well, as not all aspects can be full controlled on a script, an idea or on a performance plan, it is in the course of the performance that the mental process occurs responding to what is happening in the moment.

Drawing on the idea that the result of a performance arises from the intentionality of its executors and not from a mechanical device, the author denies the possibility of mediatization of dramatic performance. Ontological distinction between mediatized and live performance is that one is a consequence of a mere physical action and the other is a mental process, led by a system of intentions. It is the mental process by which performers prepare their task that is recognized as art and that is worth of an aesthetic analysis and not "merely matter in motion", adding: "We may complain when the $\triangleleft \mathrm{Im}$ burns up in the middle of the screening and may even demand our money back. But we regard this as a technical failure, not an artistic failure."

When making these distinctions, Carroll discusses "mediatized" performance by using cinema, television and other mass-mediatized object as opposed to the performance presented on stage (in fairness Carroll was aiming to produce a response to Auslander's "Against Ontology"), putting his 
argument in extremes: there is either the "film projectionist" or the "pianist".

Failure in "Xistórias" is a product of technology break-down; that is the main reason that pushed me to specific artistic options and by consequence changed the course of the performance. As a performer, when facing this problem I am producing a mentalisation of the failure as I create a response to it. The same happens with the audience: by experiencing failure there is a transformation of emotions, providing space for a new reading of meaning, bringing forward changes in the work of art. When I am adding the possibility of failure as an artistic option, I am not saying that we have pushed it to happen (in fact we were trying not to fail); we were hoping to transform our greatest weakness to a strong feature, in other words using a popular saying: "If you can't beat them, join them!.".



Figure 4: Still from performance Xistórias: performing and broadcasting in Aigra Nova (Schist Village)

\section{CONCLUSION}

Erwin Piscator, in the beginning of 20th century, wrote odes to technology as a means to produce political enlightenment in the audience. Visual aids, such as films and light design, were considered to be powerful tools to express an ideology. Facing major problems related to Internet service, throughout the creative process of "Xistorias", I have changed the project's priorities and decide to develop, along with aesthetic solutions, a political awareness towards the problem of digital exclusion.

We were desperately in search of a signal. Literally. We walked up and down the villages mapping each spot where we could find a strong enough signal; several gaps were tracked, the signal could jump from zero up to $3 \mathrm{Mbit} / \mathrm{s}$ in a second and down again at each step made; never certain on signal stability. But this was not only our problem; this was also the community's problem. As more people came to know about the goals of the project and the problems we were facing, more and more decided to join us. They were experiencing those problems for years and saw in the project an opportunity to take action against Internet Service providers that were increasing the prices and contributing towards a deeper isolation.

We went back to the original plan, trying to resolve whatever was possible, treating technological devices as fragile animals that any moment could perish or as a strong opponent whose job was to make us feel miserable.

The computer programmer went back to programming VLC and designed a lighter version that would need less signal to work. There was an effort to produce an aesthetic based on low tech images for the broadcast (see figures 4 and 5); based on light design and on quality of movement.

It was also decided that the quest for signal in the villages would be transformed into a choreography in space. We would work on the idea of leading the audience to an adventure to find the signal; presenting them the frustration of wanting to communicate and being cut off of any means, at the same time we played with the possibility of maintaining oral storytelling through the use of Skype.



Figure 5: Still from the performance Xistórias: streaming to Lisbon

In Lisbon, an nervous audience waited for the moment of contact that was about to happen but failed at each time the connection was made. When finally the moment of connection was achieved, Qik died, leading to more frustration and anger. But is it not this transformation of the moment, that allows the accident that pushes the performance towards a liminal experience as discussed by Fischer-Lichte? Is is not a mental process when the performer and the audience are facing the failure, as argued by Noël Carroll? 
Digital tools can bring transformation to performance practice much more deeply than light design or film being displayed on a scene; it may determinate its essence. These transformations can be perceived also from a social-cultural point of view: digital tools provide a promise of easiness, accessibility, extension of the body and, in a way, it provides a sense of intimacy, proximity and recognition by establishing common means for human interaction.

During my artistic research, as said before, I explored low tech devices, producing low-tech images - images that can be characterized by being of low technical quality, not concerned with framing or editing, very different from television or films, thus, uses an aesthetic that is more common to be found on home videos, family photos, video conferences, etc. Nevertheless, they only exist and can be recognized due to our (contemporary society) intimate relation with technology.

\section{REFERENCES}

Auslander, P. (1997), Against Ontology: making distinctions between live and the mediatized in Performance Research 2, N. 3, pp 50-55.

Carroll, N. (2009), Philosophy and Drama: performance, interpretation, and intentionality in Staging Philosophy, ed. Krasner David e Saltz David Z., Michigan , The University of Michigan Press.

Fischer-Lichte, E. (2004), Culture as Performance: developing a concept in Sinais de Cena N. ${ }^{\circ} 4$, Lisboa, Campo das Letras.

Fischer-Lichte, E. (2008), The Transformative Power of Performance: A new aesthetics, Oxon, Routledge.

McAlpine, S. (1990), Visual Aids in the production of the first Piscator-Bühne 1927-28, Frankfurt/M., Bern, New York, Paris, Peter Lang. 